\title{
Economic Preferences and Obesity among a Low-Income African American Community
}

\section{Introduction}

The prevalence of obesity has reached epidemic proportions in the US. ${ }^{1}$ Data from the National Health and Nutrition Examination Survey (NHANES) indicate that approximately onethird (32.2\% of men and 35.5\% of women) of US adults are considered obese, with a Body Mass Index (BMI), BMI $\geq 30$ (Flegal et al., 2010). Developing a full understanding of the factors leading to obesity is particularly important since obesity increases the risk of numerous chronic diseases (e.g., coronary heart disease, type 2 diabetes, hypertension), leads to higher medical care costs (Finkelstein et al., 2008), and even premature death. ${ }^{2}$ Risk factors for obesity are numerous, including insufficient physical activity and an unhealthful diet, genes, economic and health conditions, and smoking among others (Anderson et al., 2009). We contribute to the discussion by investigating the possible role of one set of factors, individual risk and time preferences, on the tendency to be obese among a population of low-income African Americans in the United States.

Previous research has found that lifestyle interventions can result in weight loss and decreased risk for morbidity (Diabetes Prevention Program Research Group, 2002). However, an individual's willingness to undertake and maintain the necessary lifestyle changes is impacted by numerous factors at both the individual (e.g., self-efficacy) and socio-environmental (e.g., unsafe neighborhoods) levels (Sallis et al., 2006). Further, some individuals may be more responsive to changes in incentives than others (e.g., Courtemanche, Heutel and McAlvanah 2014).

\footnotetext{
${ }^{1}$ Differences in prevalence of obesity among black, white, and Hispanic adults - United States, 2006-2008, in MMWR2009, Centers for Disease Control and Prevention. p. 740-744.

2008 Physical activity guidelines for Americans. U.S. Department of Health and Human Services, cited August 2 2009. Available from: http://www.health.gov/paguidelines/default.aspx.
} 
Ethnic minority populations, such as African Americans, are more likely to be physically inactive and experience higher levels of obesity and other chronic conditions than their ethnic majority counterparts (Barnes 2007; Flegal et al., 2010; Shuval et al., 2011). This disparity may be attributed in part to socio-economic status, lack of access to healthful foods and exercise facilities, and differential access to and utilization of healthcare services (Faridi et al., 2010; Joynt, Orav and Jha 2011; Orsi, Margellos-Anast and Whitman 2010).

However, little is understood about why some individuals in such settings become obese and others do not. In addition to these broader factors, understanding individual characteristics, such as how individuals evaluate risk and make inter-temporal tradeoffs is important for understanding health decisions. We extend the literature by eliciting economic preferences using high-stakes incentivized activities (for many of the subjects in our sample, the experimental stakes represent $0.5-1 \%$ of their annual income), where participants face choices that have salient financial consequences, and relate these preferences to objectively-measured BMI. We focus on a low-income, predominantly African American community.

Consider, for clarity, the decision to become more physically active, which is a healthrelated activity. Engaging in physical activity is costly in the present (assuming the immediate energy expenditure outweighs any immediate pleasure from physical activity), but has a possible future gain in terms of decreased obesity and health risks for various chronic diseases. If the decision of whether to become physically active is made in isolation, then a simple hypothesis would be that individuals who are more risk tolerant would be less likely to engage in physical activity, choosing instead to bear any risks associated with a sedentary lifestyle. For very lowincome residents of a high-crime neighborhood such as ours, there may be immediate risks connected with physical activity, such as the lack of safety while outdoors, or the potential for 
physical injury in the absence of health insurance. These immediate risks may then lead to the hypothesis that individuals who are more risk tolerant are more likely to engage in physical activity, and so less likely to be obese. Thus, for our population of interest, the overall relationship between risk preferences and obesity is an open empirical question.

Considering time preferences, one would propose that individuals who are more patient are more likely to increase physical activity and consume a healthful diet (both leading to reduced obesity risk) because they would be more willing to sacrifice immediate pleasures for future rewards. We investigate these hypotheses by examining the relationship of incentivized measures of risk tolerance and patience with obesity.

Other studies have investigated the relationship between health and such preferences using hypothetical decisions, where time or risk preferences are revealed based on how subjects say they would behave in a hypothetical situation (e.g., Barsky et al., 1997; Borghans and Golsteyn 2006; Dohmen et al., 2011 among others). Hypothetical risk tolerance is positively associated with smoking (Barsky et al., 1997; Dohmen et al., 2011), chronic diseases (Guiso and Paiella 2004), drinking, a lack of insurance (Barsky et al., 1997) and poor health (self-reported, e.g., van der Pol 2011). However, conflicting results have been reported. For example, hypothetical risk tolerance has also been found to be positively associated with the likelihood and quantity of purchased life, health, and casualty insurances (Guiso and Paiella 2004).

A number of studies have examined how individuals discount health outcomes by having individuals make a series of hypothetical decisions regarding life expectancy or health quality (e.g., see Chapman 2003 and the papers discussed within). These studies indicate that intertemporal health decisions are sensitive to context and subject to biases found in the study of 
monetary time preferences. ${ }^{3}$ Further, individuals tend to be more impatient, or to discount the future more heavily, when making health decisions.

However, the evidence relating patience to health behaviors is mixed. Hypothetical measures of patience do not correlate strongly with preventive health choices (e.g., Chapman and Coups 1999; Fuchs 1982), though they do correlate with self-reported health status (e.g., van der Pol 2011). Empirical evidence suggests that patience may be negatively related to BMI (e.g., Borghans and Golsteyn 2006; Courtemanche, Heutel and McAlvanah 2014; Ikeda, Kang and Ohtake 2010). Often these estimates use proxies for patience, such as self-reported evaluations of how well a person manages their finances (Borghans and Golsteyn 2006), debt (Ikeda, Kang and Ohtake 2010) or willpower (Zhang and Rashad 2008) rather than by using direct measures of patience. The strength of the relationship observed in the data is sensitive to the choice of proxy.

Only a few papers use incentivized measures to examine the impact of economic preferences on health outcomes (particularly obesity). ${ }^{4}$ Most of the current studies consider either risk tolerance or patience in isolation. For example, an incentivized measure of patience at age four predicts obesity later in life (Seeyave et al., 2009). For a sample of high-income, welleducated adults and students in Williamsburg, Virginia, individuals who are more risk tolerant are more likely to engage in smoking and heavy drinking and are more likely to be obese (Anderson and Mellor 2008), but patience is not considered. In a sample of Boston, Massachusetts adults, patience is negatively associated with BMI and smoking, while positively correlated with physical activity and diet (Chabris et al., 2008), but risk preferences are not considered. For the same community considered here, Leonard et al. (2013) relate risk and time

\footnotetext{
${ }^{3}$ Regularities include the high magnitude and variability of discount rates, higher estimated discount rates for short timespans, and lower discount rates for losses among others.

${ }^{4}$ Using a different approach, several studies have used behavioral insights to either propose or design health-related interventions (e.g., Charness and Gneezy 2009; Epstein et al., 1990; Schnier et al., 2013) or to examine the importance of incentives for healthcare providers (Hennig-Schmidt, Selten and Wiesen 2011).
} 
preferences with self-reported physical activity 'stages of change.' We find that individuals who are more risk tolerant and patient are more likely to be in an advanced physical activity stage.

The closest study to ours is Sutter et al. (2013) who use a sample of Austrian children and adolescents. They find support for a weak, positive relationship between impatience and BMI, and a strong, positive relationship between risk tolerance and BMI.

We consider both risk and time via incentivized tasks for a different sample: low-income African Americans. Further, as in Sutter et al. (2013), we note that it is particularly important to simultaneously control for both time and risk preferences because the health-related decisions of interest involve both dimensions.

Thus, the evidence is building that risk tolerance and impatience are positively related to obesity. However, the robustness of these effects across populations, empirical specifications, and preference measures remains an open empirical question, to which we contribute.

We conduct a lab-in-field experiment where we implement incentivized measures of risk tolerance and patience. Additionally, we objectively collect height and weight information in order to compute BMI. We find that risk tolerance is positively related with increased obesity risk. The positive relationship is driven by the most risk tolerant individuals. We do not find an independent relationship between experimentally-elicited patience and obesity in this sample. However, there is a significant interaction effect between risk aversion and patience that indicates that more patient people have a stronger relationship between risk aversion and obesity.

We will now turn to a discussion of the methods used in this study in Section 2. Section 3 discusses the results and Section 4 concludes. 


\section{Methods}

\subsection{Selection and Description of Participants}

This study utilizes data collected as part of a large cross-sectional, longitudinal research project. The overall purpose of that project is to study the effects of publicly driven investment in a low-income (median=\$19,939), minority (70\% African American and 26\% Hispanic) neighborhood (US Census, 2005-2009 American Community Survey 5 Year Estimates). The neighborhood, located less than two miles southeast of downtown Dallas, Texas, has approximately 20,000 residents. We analyze cross-sectional data from the second phase of the study which includes information from both the economics experiments and objectively measured BMI. Leonard et al. (2011) provides a complete project description, including the sampling strategy. The overall sample is a geographically-weighted random sample of households in the neighborhood.

The subsample used in this study consists of 496 participants who completed a detailed survey including socio-economic data, lifestyle behaviors and anthropometric measures; and 198 of these 496 participants were randomly selected to participate in economic experiments, including the preference-elicitation tasks.

T-tests were conducted to compare the mean characteristics of the sample that participated in the economic experiments and the sample that completed only the survey and obesity measures. The two samples were not statistically different with respect to gender ( $t=-$ $0.37)$, age ( $\mathrm{t}=1.19)$, marital status ( $\mathrm{t}=-0.53)$, income ( $\mathrm{t}=0.15)$ or $\mathrm{BMI}(\mathrm{t}=0.17)$. In two cases, participants in the economic experiments had missing data, leaving 196 complete observations for time and risk preferences. After accounting for missing data in the dependent variable (2 observations) and independent variables (40 observations), 154 participants were found to have 
fully completed both lifestyle behavior measurements, anthropometric measures, and the incentivized preference elicitations.

Data were collected during October 2009 through February 2010 in a research field station in the neighborhood. The research in the community began in 2006 and the field station was a rented storefront in a central location. The study was community based and community members who were trusted by the community were an integral part of the research team. This enhanced enrollment and created a sense of trust among the both the community at large and the study participants. All participants were compensated for their time. Subjects received $\$ 30$ for the completing the survey. They received an additional $\$ 20$ show-up fee for economic experiments. Additionally, the incentivized preference elicitations described below provided the opportunity for participants to earn additional compensation (mean $=\$ 50.42, \mathrm{SD}=\$ 21.52$ ).

\subsection{Collection of BMI}

Participants' weight and height were measured by trained personnel using a calibrated digital scale and stadiometer respectively. BMI was calculated using the standard formula: $\mathrm{kg} / \mathrm{meters}^{2}$. Participants were categorized into five groups: Not overweight or obese—which includes both underweight and normal weight categories (<24.9); Overweight (25-29.9); Obesity I (30.0-34.9); Obesity II (35.0-39.9); Obesity III ( $\geq 40)$, based on National Institute for Health guidelines. ${ }^{5}$ The underweight and normal weight categories were combined because there were only 5 participants ( $3.25 \%$ of the sample) falling into the underweight category.

\subsection{Collection of Incentivized Measures of Economic Preferences}

Participants randomly selected to participate in the experimental portion of the study arrive at the study location, receive an identification number, and complete the written informed

\footnotetext{
${ }^{5}$ Classification of overweight and obesity by BMI, waist circumference and associated disease risks. US Department of Health and Human Services, National Institute of Health. Obesity education initiative.

http://www.nhlbi.nih.gov/health/public/heart/obesity/lose_wt/bmi_dis.htm. Accessed August 1, 2014.
} 
consent. The experimental sessions consist of a series of nine activities, all of which are contextfree and involve choices over real money outcomes. Decisions always proceed in the same order, with no feedback between decisions. ${ }^{6}$ The risk and time preference decisions are the focus of this paper. One of the activities is randomly chosen for payment in cash at the end of the session. All experimental materials are available upon request.

Risk Tolerance: Risk preferences can be measured using a variety of methodologies (see e.g., Charness, Gneezy and Imas 2013). The method used in this study has its origins in Binswanger (1980) and Eckel and Grossman (2008). This method presents a pictorial representation of the financial gambles, which was developed for use in low-literacy populations (Eckel et al., 2012).

Several elicitation methods have been proposed in the literature, there is little agreement as to the preferred elicitation method. Since our population of interest tends to have low levels of education, we have chosen to implement a visual elicitation method, shown to have less noise than a multiple-price list format for low-math literacy populations (Dave et al., 2010). The decision form for this task is shown in Figure 1, below.

\section{[Figure 1]}

Specifically, the risk preference elicitation presents the participant with six possible fiftyfifty gambles which are increasing in both expected value and variance (risk), with the final choice (6) involving only an increase in variance. The low and high payoffs for these gambles are: (1) $\$ 40 / \$ 40$ - a sure thing, (2) $\$ 30 / \$ 60$, (3) $\$ 20 / \$ 80$, (4) $\$ 10 / \$ 100$, (5) $\$ 0 / \$ 120$ and

\footnotetext{
${ }^{6}$ In order, the tasks are: risk preferences, correlated risk within a group, preferences over positively skewed risky alternatives, time preferences, two comparative dictator decisions (dictator games with four different targets), a trust game, and two versions of the solidarity game. These measures are included in the study to examine other aspects of the community and are not relevant for the current analysis. None of these measures are statistically significant in or alter the robustness of the following analysis. Solidarity results are available in de Oliveira, Eckel and Croson (2014). Other studies have examined the impact of peer effects and social network on obesity (e.g. Christakis and Fowler 2007).
} 
(6) $-\$ 10 / \$ 130$. Each participant chooses the one gamble they most prefer, indicating their willingness to trade off between a higher reward (the potential for earning more money) and a higher risk (from the higher variance). Only those with extremely low risk tolerance will choose gamble 1, and only risk-seeking individuals should choose gamble 6, which constitutes only an increase in variance compared with gamble 5. The choice of the gamble allows us to infer a level of risk tolerance (for details see Binswanger 1980, Eckel and Grossman 2008). The risk preference data are thus coded one through six, corresponding to the gamble choice. Higher numbers therefore indicate increasing risk tolerance.

Patience: Time preference elicitations can be traced to survey work in Thaler (1981). Modern protocols originate with Coller and Williams (1999), which we present in a simple pictorial form (Eckel et al., 2011; Eckel, Johnson, and Montmarquette 2005).

In the time preference elicitation, we use participants' choices between sooner and later amounts as a measure of their willingness to wait for delayed rewards. Participants make six separate choices between receiving $\$ 50$ tomorrow or a larger sum of money $(\$ 51, \$ 55, \$ 60, \$ 70$, $\$ 100$ or $\$ 150$, respectively) six months from tomorrow. The decision form is shown in Figure 2.

[Figure 2]

Both the sooner and the later payment dates are in the future to minimize confounding effects of trust in the experimenter, and to avoid the problem of impulsiveness (there is no 'now' option). Choosing the later payment indicates a "patient choice" and the subsequent analysis will examine the number of patient choices individuals were willing to make as a measure of their patience. ${ }^{7}$ The more patient choices a participant makes, the less he discounts the future. For example, if a participant chose to wait only once - for the largest future amount - then he would

\footnotetext{
${ }^{7}$ We are, unfortunately, not able to empirically estimate discount factors for this population due to the high number of participants who are never willing to make a patient choice. However, the number of patient choices provides a consistent ranking: individuals who make more 'patient choices' have larger discount factors (are more patient).
} 
be very impatient and would discount the future a great deal. If he made six patient choices, even for the smallest future amount, then he would be very patient.

Time preference data are coded by the total number of patient choices. With additional assumptions concerning individual preferences, it is possible to calculate the discount factor for individuals and the CRRA for risk. We have chosen to make the minimal assumptions possible rather than imposing additional structure which may not be appropriate. Specifically, we assume that the individuals choice is revealed preferred to the other options.

\section{Results}

\subsection{Descriptive Results}

While obesity is known to be a public health concern in low-income, minority communities, little empirical evidence exists regarding the economic risk and time preferences in these communities, or their relationship to obesity. Table 1 provides a description of the sample and all variables used for this analysis. Figure 3 shows the distribution of weight status categories in this sample (Panel A) as well as the distribution of risk tolerance (Panel B) and patience (Panel C).

\section{[Table $1 \&$ Figure 3]}

For the dependent variable, BMI, we see that the average BMI is 31.8 , which is indicative of obesity. Over two-thirds of our sample is categorized as either overweight or obese, with approximately $15 \%$ of the sample classified as 'Obese III,' the most severe weight status classification.

The participants in this study exhibit high levels of risk aversion, with $64.28 \%$ of the sample willing to take on little or no risk (choosing Gambles 1 or 2). Risk-neutral behavior is 
exhibited by only $6.49 \%$ of the sample and $3.25 \%$ reveal a preference for risk-seeking behavior in this decision environment.

The results of the time preference elicitation indicate high levels of impatience in the sample, with over $40 \%$ of the sample never willing to wait for the larger and later payoff. Eleven percent are only willing to wait for the larger and later payoff when their investment will triple in six months. Another $21.4 \%$ of the sample require that their investment double before they were willing to make the patient choice.

In terms of demographics, our sample is predominantly African American, with only 5\% Hispanic. Forty-one percent of the subjects are male, and the average age is 42 years. Only $23 \%$ of the sample are currently married and over half have children under the age of eighteen living at home. This is a low-income population, with almost half of the subjects earning under $\$ 10,000$ a year (annual household income) and 64\% reporting that they have been unemployed within the past 12 months.

In addition to our independently-confirmed BMI, we also have self-reported health measures which could impact BMI. Almost $40 \%$ of our sample rates their health as either excellent or very good, and only $2 \%$ of the sample reports that they are in poor health, none of which are in the Obese III category.

High levels of impatience, like those observed in our sample, are thought to be consistent with high levels of obesity: the costs of prevention are in the present and any associated risks are in the future. We will now turn to an individual-level analysis to examine the possible relationship between risk tolerance, patience and obesity. 


\subsection{Correlates of Obesity}

Following the public health literature, we use weight status category as the dependent variable. ${ }^{8}$ We estimate an ordered logistic regression model using STATA 13 (STATA, College Station, Texas). The coefficients are reported in Table 2. For ease of interpretation, the marginal effects for the relationship between the incentivized preference measures and BMI are reported in Table 3. The marginal effects give the percentage point change in the likelihood of an individual with average characteristics being classified in a particular BMI category for a 1 unit change in the explanatory variable (i.e., risk tolerance or patience). We include controls for demographics and health status.

\section{[Tables $2 \& 3]$}

Confirming the results of Anderson and Mellor (2008), we see that increased risk tolerance is associated with a higher BMI (controlling for covariates). ${ }^{9}$ The marginal effects in Table 3 indicate that each step-level increase in risk tolerance is associated with a $5.8 \%$ decrease in the likelihood of being under/normal weight and a 3.8\% increase in the likelihood of being classified as Obese III.

In comparison to Sutter et al. (2013), patience does not show a statistically significant association with BMI in our sample. It may be that the elicited time preferences are not related to obesity in this sample or it may be a consequence of the limited variation in the data due to the substantial number of subjects who are never willing to wait for the larger and later payoff. To confirm that the non-significant time preference result is not due to multicollinearity, we check

\footnotetext{
${ }^{8}$ www.nhlbi.nih.gov/health/public/heart/obesity/lose_wt/bmi_dis.htm

${ }^{9}$ The qualitative results are robust to excluding all of the covariates except 'male.' For a logit model with only risk tolerance, patience, and male as explanatory variables the coefficients (standard error) are $0.25(0.11)$ for risk tolerance, $0.10(0.09)$ for patience and -1.05 (0.31) for male. Further excluding male reduces the significance on risk tolerance to the $10 \%$ level.
} 
the correlation between the elicited risk and time preferences measures, which is not significant in this sample (corr=0.0313, $\mathrm{p}=0.8946$; Pearson $\left.\chi^{2}=25.6397, \operatorname{Pr}=0.693\right)$.

Socio-demographic characteristics show little association with the obesity measures, but this is likely due to the homogeneity of the sample. For example, $95 \%$ of the sample is African American, $77 \%$ are not married, and $48 \%$ have incomes less than $\$ 10,000$ a year (see Table 1 ). Alternate income specifications are similarly not significantly related to obesity. ${ }^{10}$ We see that men are less likely to be obese, which is consistent with the literature (Ogden et al., 2014). Turning to the self-reported health status controls, we find that individuals with health insurance or poorer health status are more likely to be obese.

To more fully examine the relationship between risk tolerance, patience and obesity, we re-estimate the model in Table 2, allowing for a non-linear impact of risk tolerance. Results are shown in Table 4, with the accompanying marginal effects shown in Appendix Table 1.

\section{[Table 4]}

Examining Table 4, we see that the positive relationship between risk tolerance and obesity is driven by the most risk-tolerant individuals, particularly the risk-neutral, expectedvalue maximizing individuals who selected Gamble 5. However, likelihood-ratio tests do not indicate an increase in the explanatory power of the model, suggesting that the linear model remains a reasonable approximation of the relationship. ${ }^{11}$ Risk neutrality in the risk experiment is associated with a $14.5 \%$ increase in the likelihood of being classified as Obese II and a $26.7 \%$ increase in the likelihood of being classified as Obese III.

One source of individual heterogeneity in patience could be different reactions to an uncertain future. It is therefore important to consider a possible interaction effect between risk

\footnotetext{
${ }^{10}$ Alternate specifications include: a dummy variable for low-income ( $\$ 10 \mathrm{~K}$ or $\$ 20 \mathrm{~K}$ threshold), dummy variables for each income category, or Income ${ }^{2}$.

${ }^{11} \chi^{2}(4)=4.88$, Prob $>\chi^{2}=0.2993$.
} 
tolerance and patience. For this analysis, we need to make several changes to the model specification. First, since risk tolerance is likely positively related to obesity and patience is expected to be negatively related with obesity, the expected direction and interpretation of an interaction between the two is unclear. We therefore reverse code risk tolerance into risk aversion by subtracting the chosen gamble from 7 . Thus, if the subject chooses the no-risk option they are coded as 6 , and the risk seeking choice is coded as 1 .

Second, the correlation between Patient and the interaction term is too strong to include both variables without causing multicollinearity issues (corr $=0.9227, \mathrm{p}=0.00$ ). To address this specification issue, we standardize both risk aversion and patience by subtracting their respective means. Thus positive (negative) numbers indicate the degree to which an individual's risk aversion or patience is above (below) the mean in the sample. We then interact these standardized variables.

\section{[Table 5]}

The first column includes the standardized risk aversion and standardized patience variables while the second additionally includes the interaction between the two. The remaining columns show the average marginal effects for each of the five BMI categories. Since deviations from the mean are sample-specific, we focus on the sign and significance of the variables as opposed to the magnitude.

Examining the first column, we see that risk aversion (tolerance) is negatively (positively) correlated with obesity, as before, and that there is no statistically significant relationship between the patience measure and obesity. Including the interaction term strengthens the relationship between risk aversion and obesity, with those who are both more patient and more risk averse being more likely to have a lower BMI. The negative sign on the interaction 
term can be interpreted as an indication that more patient people have a stronger relationship between risk aversion and obesity.

\section{Closing Discussion}

Consistent with previous work (Anderson and Mellor 2008; Sutter et al., 2013), we find that a higher tolerance for risk is associated with a higher BMI. This result is consistent with more risk-tolerant individuals in the elicitation activity being more accepting of the risks that come from the future health consequences of obesity. We extend their work to a new policyrelevant sample. We further show that, for this sample of participants, the relationship between risk and BMI is driven by the most risk-tolerant individuals, particularly the expected-value maximizing subjects in the sample.

Our work does differ from theirs in a few key respects. First, we use a different risk preference elicitation than either of the choice list formats used in Anderson and Mellor (2008) or Sutter et al. (2013). Dave et al. (2010) finds that there is more noise in the Holt-Laury style choice list than in the Eckel-Grossman gamble choice for those with low math literacy. We therefore chose the single-decision measure because of the low literacy rate and low math skills in our population. While stable risk preferences would indicate that results should be comparable across elicitations, if the procedure impacts the elicited risk preference then our results may not be comparable to theirs. Understanding the robustness of the relationship between risk preferences and field behavior to the preference elicitation mechanism is an important question for future work. We also use higher stakes than the previous studies. 
Next, both Anderson and Mellor (2008) and Sutter et al. (2013) calculate BMI with selfreported height and weight. ${ }^{12}$ In contrast, we measure the height and weight of each participant, avoiding the potential problems with self-reported data and providing a clean measure of BMI. Self-reported height and weight can misrepresent BMI since weight is frequently under-reported and height over-reported, especially among unemployed women (e.g., Nawaz et al., 2001). We also differ in the specification of the dependent variable. We examine the weight classifications used by public health researchers. Sutter et al. (2013) use normalized BMI as a continuous dependent variable, which ignores the non-linear relationship between BMI and health status. Anderson and Mellor (2008) predict the probability of being overweight or obese (BMI $\geq 25)$ : $46.8 \%$ of their sample fits this description. In our sample, almost $70 \%$ of the sample is either overweight or obese.

We find no statistically significant independent relationship between the elicited time preferences and obesity, suggesting caution in the interpretation of previous studies. However, we do find that time preferences impact the extent to which risk preferences were related to obesity: more patient individuals who were also risk averse, were less likely to be obese. Thus caution is warranted in assessing the external validity of previous results in low-income ethnic minority communities. Examining impulsivity in addition to impatience and their interaction with risk preferences may be a fruitful next step for research with this population.

Our results also suggest that examining the portfolio risks, both those with immediate consequences and those occurring in the future, as well as risk perceptions, would provide an interesting and potentially important avenue for future research. Using the tools of experimental economics to better understand the interaction between these preferences could provide a more

\footnotetext{
${ }^{12}$ Sutter et al. (2013) does compare the self-reported measure to one obtained from medical reports for a subsample (87/661) of their data. They find a strong correlation between self-reported data and verified data (corr $=0.92, p<$ 0.001 ), lending support to their analysis of self-reported data.
} 
rigorous framework for further study of individual health decisions. Insights could further inform and target interventions. For example, the walking school bus program in low-income communities has been shown to promote physical activity by lowering the risk associated with walking in low-income neighborhoods (Kong et al., 2009).

Additionally, the results may be viewed in light of the recent policy moves on the part of insurance companies to provide premium rebates for positive health behaviors or outcomes. On one hand, financial incentives for gym use (which move more of the rewards into the present) have been shown to increase gym use among those who were not previously regular gym-goers and to improve several health indicators (e.g., obesity, heart rate) (Charness and Gneezy 2009). However, if the incentives are not timely (i.e., a delayed reward), they might be ineffective in changing health behaviors (Volpp et al., 2011).

In our sample, patience is not independently related to obesity. Our results suggest that the rebates may be effective if they help modify the perceived risks associated with obesity. Insurance companies may be able to signal the severity of the risk by offering a reward for behaviors promoting a healthy lifestyle. Further studies might investigate the effect of insurance rebates on modifying risk perceptions associated with the health behaviors or outcomes that are being targeted.

There are some key limitations to our study and as such it should be viewed as only a preliminary investigation into the behavioral economic determinants of obesity and their link with incentivized measures of preferences. The study design is cross-sectional which prevents analysis of temporal relationships between economic preferences and obesity. Additionally, the sample is relatively homogenous from one geographic location, which impacts the generalizability of the findings (i.e., external validity). However, the low-income, minority 
sample is of high interest both because of the group's increased morbidity and mortality risk and because of the degree to which low-income individuals have access to and utilize health services.

Despite these limitations, the results of our study suggest that relationship between time and risk preferences clearly warrants further examination. Future work should continue to investigate the role economic preferences play in impacting obesity in larger more representative samples while using prospective designs to determine a causal relationship. Additional studies using validated methods of economic experiments to measure preferences and relate these preferences to health behaviors will build a body of evidence through which we can more precisely apply behavioral economic theory to make health policy recommendations.

\section{Acknowledgements}

We wish to thank Rachel Croson, Natalia Candelo Londoño, Moyo Kimathi, and Beth Pickett for assistance in study design and data collection. All research involving human subjects has been approved by the Institutional Review Boards of the University of Texas at Dallas (IRB Approval Number 08-33), University of Texas Southwestern Medical Center, and University of Texas Health Science Center at Houston Institutional Review Boards. Informed written consent for study participation was obtained from each subject. This study was funded by the National Science Foundation (NSF/SES-0827350). The study was also funded by the National Center for Research Resources (NCRR), a component of the National Institutes of Health (NIH) and NIH Roadmap for Medical Research (Grant number UL1RR024982). The contents are solely the responsibility of the authors and do not necessarily represent the official view of the NCRR or NIH. 


\section{References}

Anderson, L.R., Mellor, J.M., 2008. Predicting Health Behaviors with an Experimental Measure of Risk Preference. Journal of Health Economics 27, 1260-1274.

Anderson, L.M., Quinn, T.A., Glanz, K., Ramirez, G., Kahwati, L.C., Johnson, D.B., Buchanan, L.R., Archer, W.R., Chattopadhyay, S., Kalra, G. P., Katz, D.L., 2009. The Effectiveness of Worksite Nutrition and Physical Activity Interventions for Controlling Employee Overweight and Obesity: A Systematic Review. American Journal of Preventive Medicine 37, 340-357.

Barnes, P., 2007. Physical Activity Among Adults: United States, 2000 and 2005. Hyattsville (MD): US Department of Health and Human Services, Centers for Disease Control and Prevention.

Barsky, R.B., Kinball, M.S., Juster, F.T., Shapiro, M.D., 1997. Preference Parameters and Behavioral Heterogeneity: An Experimental Approach in the Health and Retirement Study. Quarterly Journal of Economics 112, 537-579.

Binswanger, H.P., 1980. Attitudes toward Risk: Experimental Measurement in Rural India. American Journal of Agricultural Economics 62, 395-407.

Borghans, L., Golsteyn, B.H.H., 2006. Time Discounting and the Body Mass Index: Evidence from the Netherlands. Economics and Human Biology 4, 39-61.

Chabris, C.F., Laibson, D., Morris, C.L., Schuldt, J.P., Taubinsky, D., 2008. Individual Laboratory-Measured Discount Rates Predict Field Behavior. Journal of Risk and Uncertainty 38, 237-269. 
Chapman, G.B., 2003. Time Discounting of Health Outcomes. In Time and Decision: Economics and Psychological Perspectives on Intertemporal Choice, Loewenstein, G., D. Read, and R.F. Baumeister, eds. New York, NY: Russell Sage Foundation. pp. 395-417.

Chapman, G.B., Coups, E.J., 1999. Time Preferences and Preventative Health Behavior: Acceptance of the Influenza vaccine. Medical Decision Making 19, 307-14.

Charness, G., Gneezy, U., 2009. Incentives to Exercise. Econometrica 77, 909-931.

Charness, G., Gneezy, U., Imas, A., 2013. Experimental Methods: Eliciting Risk Preferences. Journal of Economic Behavior and Organization 87, 43-61.

Christakis, N.A., Fowler, J.H., 2007. The Spread of Obesity in a Large Social Network over 32 Years. New England Journal of Medicine. 357, 370-379

Coller, M., Williams, M.B., 1999. Eliciting Individual Discount Rates. Experimental Economics 2, 107-127.

Courtemanche, C., Heutel G., McAlvanah, P., 2014. Impatience, Incentives and Obesity. Economic Journal Forthcoming. DOI: 10.1111/ecoj.12124.

Dave, C., Eckel, C.C., Johnson, C.A., Rojas, C., 2010. Eliciting Risk Preferences: When is Simple Better? Journal of Risk and Uncertainty 41, 219-243.

de Oliveira, A.C.M., Eckel, C., Croson, R., 2014. Solidarity among the Poor. Economics Letters. $123,144-148$.

Diabetes Prevention Program Research Group. 2002. Reduction in the Incidence of Type 2 Diabetes with Lifestyle Intervention or Metformin. New England Journal of Medicine 346, 393-403. 
Dohmen, T., Falk, A., Huffman, D., Sunde, U., Schupp, J., Wagner, G.G., 2011. Individual Risk Attitudes: Measurement, Determinants, and Behavioral Consequences. Journal of the European Economic Association 9, 522-550.

Eckel, C.C., Grossman, P., 2008. Forecasting Risk Attitudes: An Experimental Study Using Actual and Forecast Gamble Choices. Journal of Economic Behavior and Organization $68,1-17$

Eckel, C.C., Grossman, P.J., Johnson, C.A., de Oliveira, A.C.M., Rojas, C., Wilson, R.K., 2012. School Environment and Risk Preferences: Experimental Evidence. Journal of Risk and Uncertainty 45, 265-292.

Eckel, C.C., Grossman, P.J., Johnson, C.A., de Oliveira, A.C.M., Rojas, C., Wilson, R.K., 2011. (Im)patience among Adolescents: A Methodological Note. CBEES Discussion paper No. 10-03.

Eckel, C.C., Johnson C.A., Montmarquette, C., 2005. Saving Decisions of the Working Poor: Short- and Long-Term Horizons. Harrison, G. W, Carpenter, J., List, J.A., eds. Field Experiments in Economics (Research in Experimental Economics, Volume 10) Emerald Group Publishing Limited, pp.219 - 260

Epstein, L.H., Valoski, A., Wing, R.R., McCurley, J., 1990. Ten-Year Follow-up of Behavioral, Family-based Treatment for Obese Children. JAMA 264, 2519-2523.

Faridi, Z., Shuval, K., Njike, V.Y., Katz, J.A., Jennings, G., Williams, M., Katz, D.L., 2010. Partners Reducing Effects of Diabetes (PREDICT): A Diabetes Prevention Physical Activity and Dietary Intervention through African-American Churches. PREDICT Project Working Group. Health Education Research 25, 306-15. 
Finkelstein, E.A., Trogdon, J.G., Brown, D.S., Allaire, B.T., Dellea, P.S., Kamal-Bahl, S.J., 2008. The Lifetime Medical Cost Burden of Overweight and Obesity: Implications for Obesity Prevention. Obesity 16, 1843-1848.

Flegal, K.M., Carroll, M.D., Ogden, C.L., Curtin, L.R., 2010. Prevalence and Trends in Obesity Among US Adults, 1999-2008. JAMA 303, 235-241.

Fuchs, V.R., 1982. Time Preferences and Health: An Exploratory Study. In Fuchs, V.R. (Ed.) Economic Aspects of Health. Chicago, IL: University of Chicago Press.

Guiso, L., Paiella, M., 2004. The Role of Risk Aversion in Predicting Individual Behavior. CEPR Discussion Paper No. 4591.

Hennig-Schmidt, H., Selten, R., Wiesen, D., 2011. How Payment Systems affect Physicians' Provision Behavior-An Experimental Investigation. Journal of Health Economics 30, 637-646.

Ikeda, S., Kang, M., Ohtake, F., 2010. Hyperbolic Discounting, the Sign Effect, and the Body Mass Index. Journal fo Health Economics 29, 268-284.

Joynt, K.E., Orav, E.J., Jha, A.K., 2011. Thirty-day Readmission Rates for Medicare Beneficiaries by Race and Site of Care. JAMA 305, 675-681.

Kong, A.S, Sussman, A.L., Negrete, S., Patterson, N., Mittleman, R., Hough, R., 2009. Implementation of a Walking School Bus: Lessons Learned. Journal of School Health 79, $319-25$.

Leonard, T.C.M., Caughy, M.O., Mays, J.K., Murdoch, J.C., 2011. Systematic Neighborhood Observations at High Spatial Resolution: Methodology and Assessment of Potential Benefits. PLoS ONE 6, e20225. 
Leonard, T.C.M., Shuval, K., de Oliveira, A.C.M., Skinner, C.S., Eckel, C., Murdoch, J.C., 2013. Health Behavior and Behavioral Economics: Economic Preferences and Physical Activity Stages of Change in a Low-Income African American Community. American Journal of Health Promotion 27, 211-221.

Nawaz, H., Chan, W., Abdulrahman, M., Larson, D., Katz, D.L., 2001. Self-Reported Weight and Height: Implications for Obesity Research. American Journal of Preventive Medicine 20, 294-298.

Ogden, C.L., Carroll, M.D., Kit, B.K., Flegal, K.M., 2014. Prevalence of Childhood and Adult Obesity in the United States, 2011-2012. JAMA 311, 806-814.

Orsi, J.M., Margellos-Anast, H., Whitman, S., 2010. Black-White Health Disparities in the United States and Chicago: A 15-year Progress Analysis. American Journal of Public Health 100,349-56.

Sallis, J.F., Cervero, R.B., Ascher, W., Henderson, K.A., Kraft, M.K., Kerr, J., 2006. An Ecological Approach to Creating Active Living Communities. Annual Review of Public Health 27, 297-322.

Schnier, K.E., Cox, J.C., McIntyre, C., Ruhil, R., Sadiraj, V., Turgeon, N., 2013. Transplantation at the Nexus of Behavioral Economics and Health Care Delivery. American Journal of Transplantation. 13, 31-35.

Seeyave, D., Coleman, S., Appugliese, D., Corwyn, R., Bradley, R., Davidson, N., Kaciroti, N., Lumeng, J., 2009. Ability to Delay Gratification at Age 4 Years and Risk of Overweight at Age 11 Years. Archives of Pediatrics and Adolescent Medicine 163, 303-308. 
Shuval, K., DeVahl, J., Tong, L., Gimpel, N., Lee, J., DeHaven, M., 2011. Metabolic Syndrome, Anthropometry, and Meeting the 2008 Physical Activity Guidelines in African American Church Members, South Dallas, Texas. Preventing Chronic Disease 8, A18.

Sutter, M., Kocher, M.G., Rützler, D., Trautmann, S., 2013. Impatience and Uncertainty: Experimental Decisions Predict Adolescents’ Field Behavior. American Economic Review 103, 510-531.

Thaler, R.H., 1981. Some Empirical Evidence on Dynamic Inconsistency. Economics Letters 8, 201-207.

van der Pol, M., 2011. Health, Education and Time Preference. Health Economics 20, 917-929. Volpp, K.G., Asch, D.A., Galvin, R., Loewenstein, G., 2011. Redesigning Employee Health Incentives-Lessons from Behavioral Economics. New England Journal of Medicine 365, 388-90.

Zhang, L., Rashad, I., 2008. Obesity and Time Preference: The Health Consequences of Discounting the Future. Journal of Biosocial Science 40, 97-113. 
Tables

Table 1. Characteristics of 154 Fair Park residents

\begin{tabular}{|c|c|c|c|}
\hline Variable & Mean & $\begin{array}{l}\text { Std. } \\
\text { Dev. }\end{array}$ & Description \\
\hline BMI & 31.68 & 11.30 & Measured BMI, kg/meters ${ }^{2}$ \\
\hline Risk Tolerance & 2.31 & 1.38 & Gamble choice, 1-6 \\
\hline Patience & 1.55 & 1.68 & Number of patient choices, $0-6$ \\
\hline Hispanic & 0.05 & 0.21 & $\mathrm{DV}=1$ if Hispanic, 0 otherwise \\
\hline Male & 0.41 & 0.49 & $\mathrm{DV}=1$ if Male, 0 otherwise \\
\hline Age & 42.29 & 12.00 & Age in years, $18-77$ years \\
\hline Married & 0.23 & 0.42 & $\begin{array}{l}\mathrm{DV}=1 \text { if currently married, } \\
0 \text { otherwise }\end{array}$ \\
\hline Kids & 0.56 & 0.50 & $\begin{array}{l}\mathrm{DV}=1 \text { if children }<18 \text { years living } \\
\text { at home, } 0 \text { otherwise }\end{array}$ \\
\hline No Insurance & 0.34 & 0.47 & $\begin{array}{l}\mathrm{DV}=1 \text { if no current health } \\
\text { insurance, } 0 \text { otherwise }\end{array}$ \\
\hline Income & 0.23 & 1.69 & Categorical income variable, $1-8$ \\
\hline 1 Less than $\$ 10,000$ & & & $48.05 \%$ \\
\hline $2 \$ 10,000$ to less than $\$ 20,000$ & & & $23.38 \%$ \\
\hline $3 \$ 20,000$ to less than $\$ 30,000$ & & & $10.39 \%$ \\
\hline $4 \$ 30,000$ to less than $\$ 40,000$ & & & $7.14 \%$ \\
\hline $5 \$ 40,000$ to less than $\$ 50,000$ & & & $2.60 \%$ \\
\hline $6 \$ 50,000$ to less than $\$ 60,000$ & & & $5.19 \%$ \\
\hline $7 \$ 60,000$ to less than $\$ 70,000$ & & & $1.95 \%$ \\
\hline $8 \$ 70,000$ to less than $\$ 80,000$ & & & $1.30 \%$ \\
\hline Unemployed & 0.64 & 0.48 & $\begin{array}{l}\mathrm{DV}=1 \text { if unemployed in the last } \\
\text { year, } 0 \text { otherwise }\end{array}$ \\
\hline Health Status ${ }^{a}$ & 2.77 & 0.99 & Self-reported health status, $1-5$ \\
\hline 1 Excellent & & & $11.04 \%$ \\
\hline 2 Very Good & & & $27.27 \%$ \\
\hline 3 Good & & & $37.01 \%$ \\
\hline 4 Fair & & & $22.73 \%$ \\
\hline 5 Poor & & & $1.95 \%$ \\
\hline Health Limits Activity ${ }^{b}$ & 2.21 & 4.05 & $\begin{array}{l}\text { Number of days of where poor } \\
\text { health prevents activity, } 0-30\end{array}$ \\
\hline ER Trips $^{c}$ & 1.36 & 1.77 & $\begin{array}{l}\text { Number of ER trips in the past } \\
\text { year due to illness, } 0-12\end{array}$ \\
\hline
\end{tabular}

a "In general, your health is: Excellent, Very good, Good, Fair, Poor."

$\mathrm{b}$ "During the past month, how many days did poor mental or physical health keep you from doing your usual activities (for example, you were too sick to go to work or complete household chores)? Times"

c "How many times in the past year has a member of your household had to visit the emergency room for an illness (such as fever, infection, virus, etc.)? Times" 
Table 2. Impact of Risk Tolerance and Patience on BMI

\begin{tabular}{|c|c|}
\hline Variable & 5 Category ${ }^{\mathrm{a}}$ \\
\hline Risk Tolerance & $\begin{array}{l}0.339^{* *} \\
(0.113)\end{array}$ \\
\hline Patience & $\begin{array}{c}0.100 \\
(0.096)\end{array}$ \\
\hline Hispanic & $\begin{array}{c}0.816 \\
(0.743)\end{array}$ \\
\hline Male & $\begin{array}{c}-0.925^{* *} \\
(0.352)\end{array}$ \\
\hline Age & $\begin{array}{c}0.012 \\
(0.015)\end{array}$ \\
\hline Married & $\begin{array}{c}0.105 \\
(0.380)\end{array}$ \\
\hline Kids & $\begin{array}{c}0.248 \\
(0.335)\end{array}$ \\
\hline No Insurance & $\begin{array}{c}-1.311^{* * *} \\
(0.352)\end{array}$ \\
\hline Income & $\begin{array}{c}0.040 \\
(0.098)\end{array}$ \\
\hline Unemployed & $\begin{array}{l}-0.218 \\
(0.354)\end{array}$ \\
\hline Health Status & $\begin{array}{l}0.461^{* *} \\
(0.174)\end{array}$ \\
\hline Health Limits Activity & $\begin{array}{l}-0.052 \\
(0.038)\end{array}$ \\
\hline ER Trips & $\begin{array}{c}0.027 \\
(0.095)\end{array}$ \\
\hline $\begin{array}{l}\text { LnL } \\
\mathrm{LR} \chi^{2}\left(\text { prob }>\chi^{2}\right) \\
\text { Pseudo } \mathrm{R}^{2}\end{array}$ & $\begin{array}{c}-218.01 \\
45.35(0.00) \\
0.0942\end{array}$ \\
\hline
\end{tabular}

Notes: $\mathrm{N}=154$.

${ }^{a}$ The 5 category regression is modeled as an Ordered Logit. Coefficients are shown, with standard errors in parentheses. Marginal effects for risk tolerance and patience are shown in Table 3. The five BMI categories are: Not overweight or obese $(<24.9)$; Overweight $(25-29.9)$; Obesity I (30.0-34.9); Obesity II (35.0-39.9); Obesity III ( $\geq 40)$. 
Table 3. Marginal effects of risk tolerance and patience on BMI

\begin{tabular}{lcc}
\hline BMI Category & $\begin{array}{c}\text { Risk } \\
\text { Tolerance }\end{array}$ & Patience \\
\hline Not overweight or obese & $-0.058^{* * *}$ & -0.017 \\
& $(0.019)$ & $(0.016)$ \\
Overweight & $-0.009^{*}$ & 0.003 \\
& $(0.004)$ & $(0.003)$ \\
Obese I & $0.010^{*}$ & 0.003 \\
& $(0.005)$ & $(0.003)$ \\
Obese II & $0.020^{* *}$ & 0.006 \\
& $(0.007)$ & $(0.006)$ \\
Obese III & $0.038^{* *}$ & 0.011 \\
& $(0.013)$ & $(0.011)$ \\
\hline
\end{tabular}

${ }^{+} \mathrm{p} \leq 0.10,{ }^{*} \mathrm{p} \leq 0.05{ }^{* *} \mathrm{p} \leq 0.01,{ }^{* * *} \mathrm{p} \leq 0.001$

Notes: $\mathrm{N}=154$.

Marginal effects to accompany Table 2. Standard errors are in parentheses. The five BMI categories are: Not overweight or obese $(<24.9)$; Overweight (25-29.9); Obesity I (30.0-34.9); Obesity II (35.0-39.9); Obesity III ( $\geq 40)$. 
Table 4. Correlates of BMI

Ordered Logit regression, standard errors in parenthesis

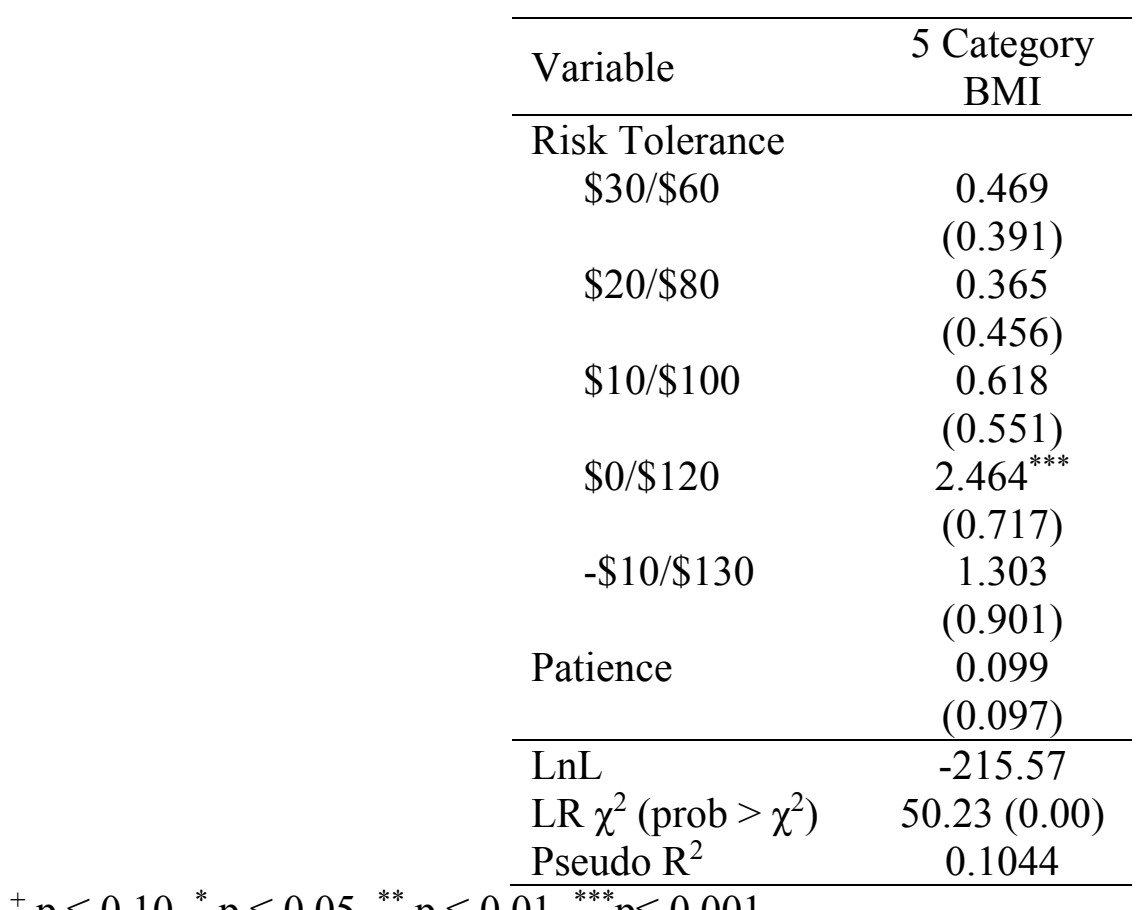

Notes: $\mathrm{N}=154$.

Controlling for all variables in Table 2. Coefficients are shown, with standard errors in parentheses. Marginal effects for risk tolerance and patience are shown in Appendix Table 1. 
Table 5. Interacting risk and patience

\begin{tabular}{cccccccc}
\hline & Coef. & Coef. & $\begin{array}{c}\text { Not Overweight } \\
\text { Or Obese }\end{array}$ & Overweight & Obesity I & Obesity II & Obesity III \\
\hline S.Risk Averse & $-0.339^{* *}$ & $-0.392^{* * *}$ & $0.067^{* * *}$ & $0.009^{*}$ & $-0.012^{*}$ & $-0.023^{* *}$ & $-0.041^{* * *}$ \\
& $(0.113)$ & $(0.118)$ & $(0.020)$ & $(0.004)$ & $(0.005)$ & $(0.008)$ & $(0.012)$ \\
S.Patience & 0.100 & 0.071 & -0.012 & -0.002 & 0.002 & 0.004 & 0.007 \\
& $(0.096)$ & $(0.098)$ & $(0.017)$ & $(0.002)$ & $(0.003)$ & $(0.006)$ & $(0.010)$ \\
S.Risk Averse*S.Patience & $\ldots$ & $-0.204^{* *}$ & $0.035^{* *}$ & $0.005^{+}$ & $-0.006^{*}$ & $-0.012^{*}$ & $-0.021^{* * *}$ \\
& & $(0.075)$ & $(0.013)$ & $(0.003)$ & $(0.003)$ & $(0.005)$ & $(0.008)$ \\
\hline LnL & -218.01 & -213.88 & & & & \\
Pseudo R & 0.0942 & 0.1114 & & & &
\end{tabular}

Notes: $\mathrm{N}=154$.

Ordered Logit, Standard errors in parentheses. Controlling for all variables from Table 2 . The 5 category regression is modeled as an Ordered Logit. The five BMI categories are: Not overweight or obese (<24.9); Overweight (25-29.9); Obesity I (30.0-34.9); Obesity II (35.0-39.9); Obesity III $(\geq 40)$. 
Figures

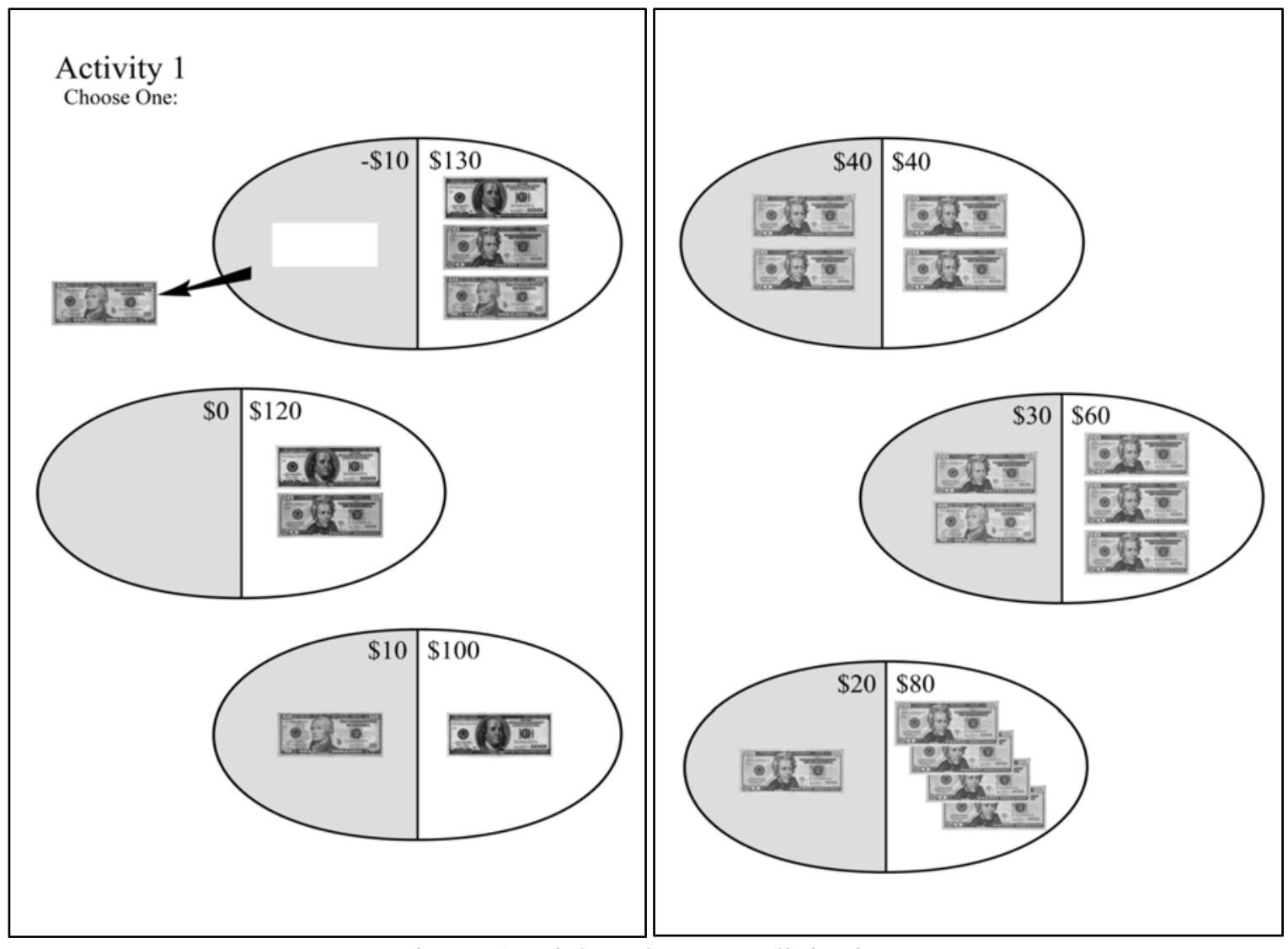

Figure 1. Risk Tolerance Elicitation 


\section{ACTIVITY 4 EXAMPLE \\ Your Choice}
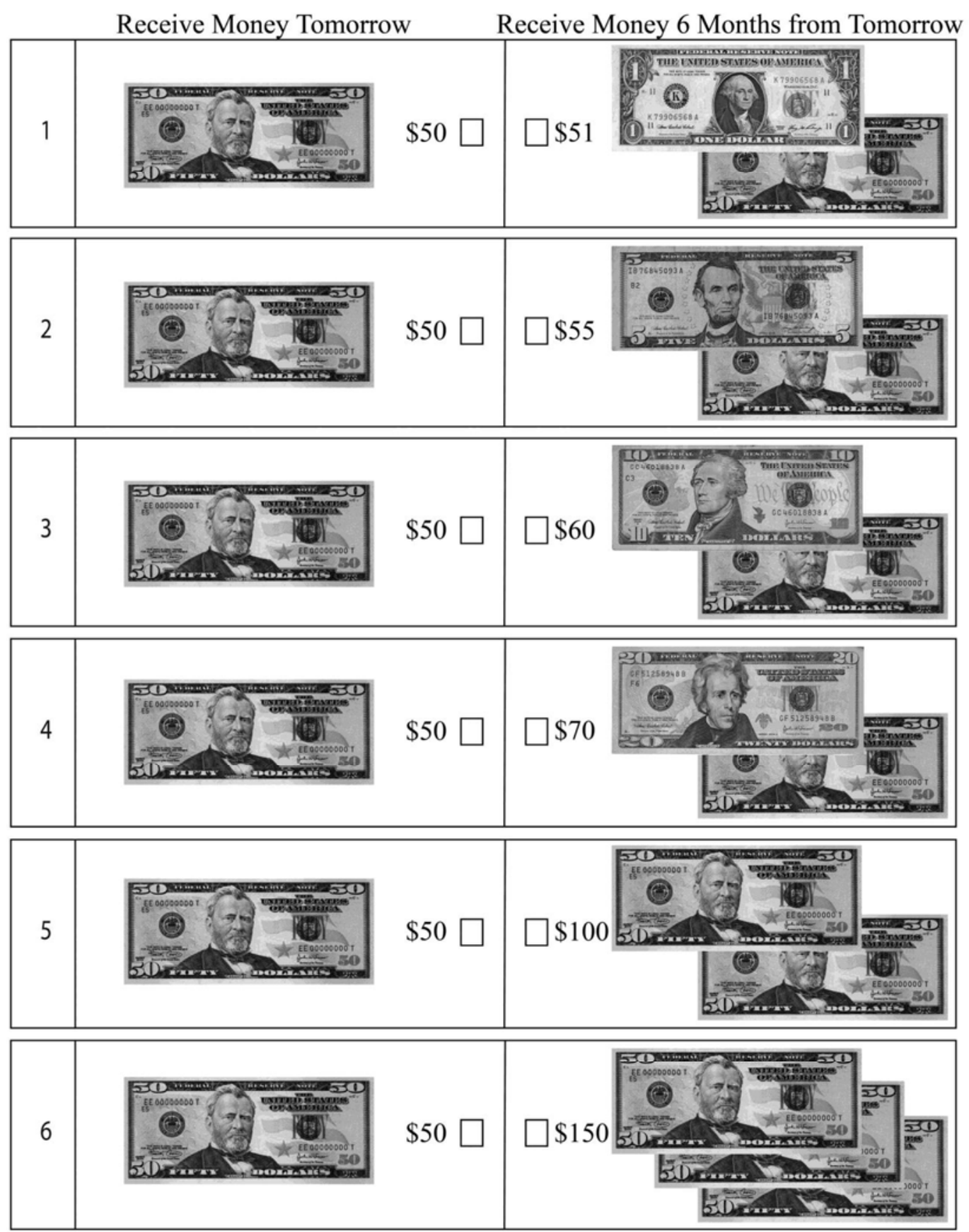

Do not turn

STOP the page until instructed.

Figure 2. Patience Elicitation 


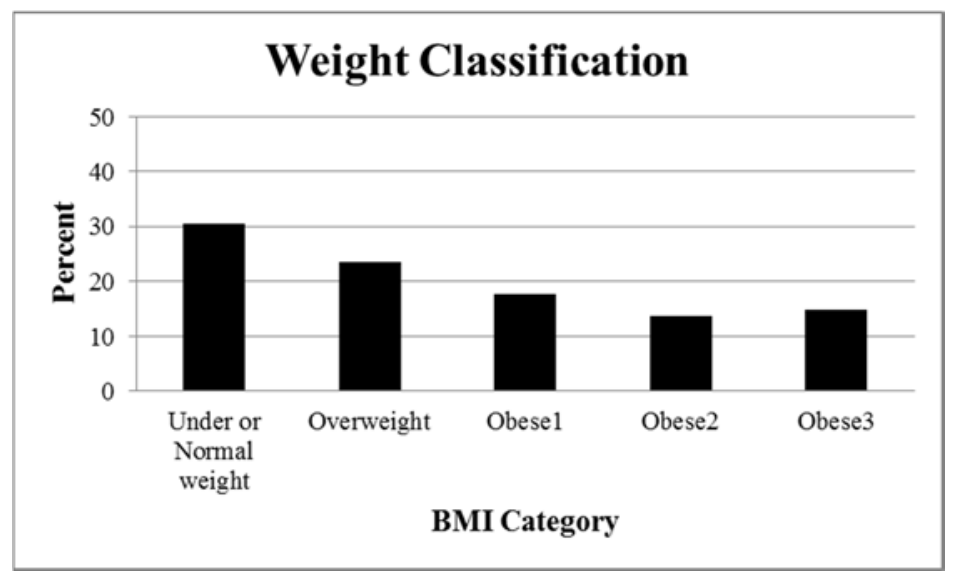

Panel A

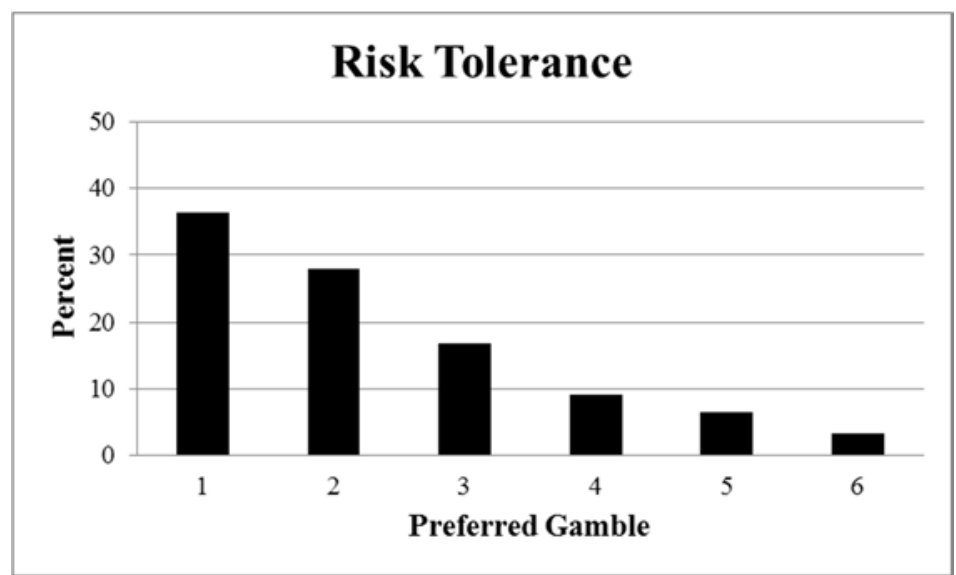

Panel B

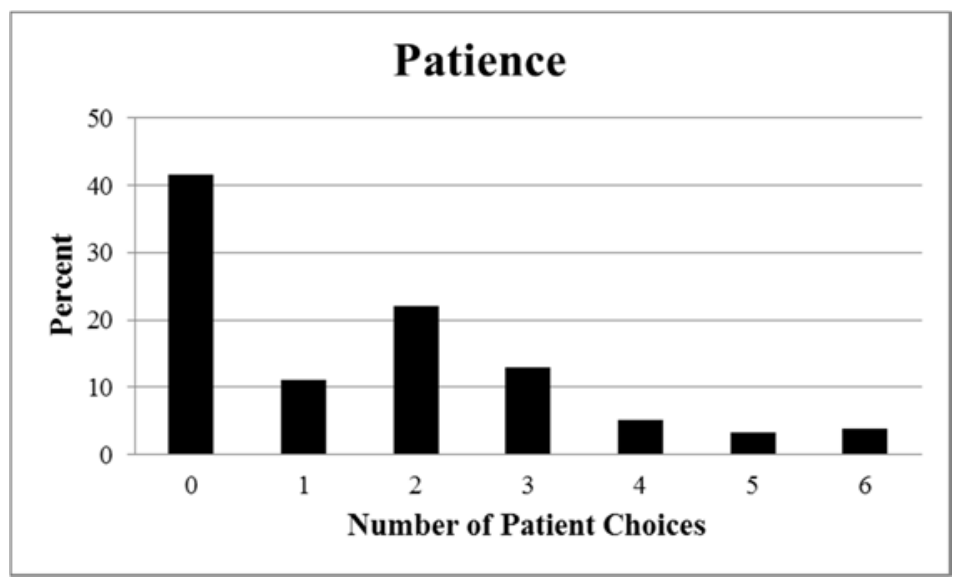

Panel C

Figure 3. Distribution of Obesity and Economic Preferences in Sample 
Appendix

Appendix Table 1. Marginal effects to accompany Table 4

Ordered Logit regression, standard errors in parenthesis

\begin{tabular}{lcccccc}
\hline \multicolumn{1}{c}{ Variable } & $\$ 30 / \$ 60$ & $\$ 20 / \$ 80$ & $\$ 10 / \$ 100$ & $\$ 0 / \$ 120$ & $-\$ 10 / \$ 130$ & Patience \\
\hline Not overweight & -0.080 & -0.062 & -0.105 & $-0.420^{* * *}$ & -0.222 & -0.017 \\
or obese & $(0.066)$ & $(0.078)$ & $(0.094)$ & $(0.120)$ & $(0.151)$ & $(0.016)$ \\
Overweight & -0.012 & -0.010 & -0.016 & $-0.064^{*}$ & -0.034 & -0.003 \\
& $(0.010)$ & $(0.012)$ & $(0.015)$ & $(0.028)$ & $(0.027)$ & $(0.003)$ \\
Obese I & 0.014 & 0.011 & 0.018 & $0.073^{*}$ & 0.039 & 0.003 \\
& $(0.012)$ & $(0.014)$ & $(0.017)$ & $(0.033)$ & $(0.029)$ & $(0.003)$ \\
Obese II & 0.028 & 0.021 & 0.036 & $0.145^{* *}$ & 0.077 & 0.006 \\
& $(0.023)$ & $(0.027)$ & $(0.033)$ & $(0.050)$ & $(0.054)$ & $(0.006)$ \\
Obese III & 0.051 & 0.039 & 0.067 & $0.267^{* * *}$ & 0.141 & 0.011 \\
& $(0.042)$ & $(0.049)$ & $(0.059)$ & $(0.076)$ & $(0.098)$ & $(0.011)$ \\
\hline
\end{tabular}

${ }^{+} \mathrm{p} \leq 0.10,{ }^{*} \mathrm{p} \leq 0.05,{ }^{* *} \mathrm{p} \leq 0.01,{ }^{* * *} \mathrm{p} \leq 0.001$ 